\title{
PRESERVATION TREATMENT GUIDE FOR AMK RANCH (UW-NPS RESEARCH CENTER)
}

\section{MARY M. HUMSTONE $\uparrow$ UNIVERSITY OF WYOMING $\uparrow$ LARAMIE}

\section{$\uparrow \quad$ AbSTRACT}

During the summer 2011 field season, the University of Wyoming American Studies Program conducted a field school at the AMK Ranch to develop a Preservation Treatment Guide for the property's historic buildings. Students and faculty documented and assessed the condition of each building on the property, researched and analyzed a range of historic preservation treatments, tested $\log$ cleaning techniques, and compiled the results of their field work, research and analysis into a 150-page document designed to guide National Park Service and University of Wyoming property managers in making decisions regarding historic buildings.

\section{BACKGROUND}

The AMK Ranch is listed on the National Register of Historic Places for its significance in the settlement of the Jackson Hole valley from 1890 to the modern era. The property is also significant for its well preserved buildings constructed in the Rocky Mountain Rustic style. The buildings retain integrity of materials, workmanship and design, and along with the landscape that surrounds them they convey the feeling and association of an early $20^{\text {th }}$ century vacation property in Grand Teton National Park.

Because of their historic and architectural significance, the buildings and structures at the AMK Ranch, as well as the property as a whole, warrant special consideration in order to preserve their character-defining features. Because the AMK Ranch is a federal property that is listed on the National Register of Historic Places, any proposed work on the buildings must be reviewed by the Wyoming State Historic Preservation Office (WYSHPO) for compliance with the Secretary of the Interior's
Standards and Guidelines for Treatment of Historic Properties. Property managers at this and other historic properties in the park need clarification on how to apply the standards to specific building conservation issues.

The Preservation Treatment Guide was developed by students and faculty in a 3-credit, upper-level undergraduate course entitled "Field Studies in Historic Preservation.”

The course was taught by University of Wyoming Research Scientist Mary Humstone, with assistance from building conservation specialist Harrison Goodall of Langley, Washington, and Grand Teton National Park Cultural Resource Specialist Katherine Longfield. Four University of Wyoming students enrolled in the course and contributed to the research and writing of the report (Figure 1).

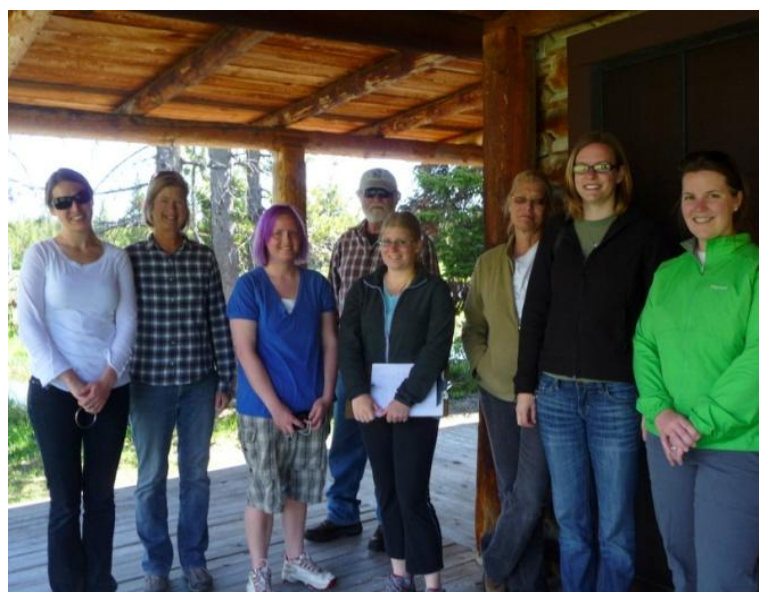

Figure 1. Project team, consisting of students, instructors and National Park Service staff, at a site visit to the LucasFabian cabin in Grand Teton National Park (Mary Humstone, 2011) 


\section{Methodology}

The four students enrolled in the course conducted several days of research on historic preservation and building conservation methods before traveling to Grand Teton National Park. The research team stayed at the UW-NPS Research Center (AMK Ranch) for nine days, most of which were spent on site.

Under the guidance of Harrison Goodall, the team completed Building Condition Assessment Forms for each of the 16 historic buildings and two historic structures on the property. The forms are designed to record the important character-defining features of each building as well as overall condition, and the condition of the roof, exterior walls and finish, foundation, windows and doors, porches and steps, site drainage and grade, and surrounding vegetation.

While most of the building assessments were based on visual inspection, the team also conducted moisture-level testing in crawl spaces below buildings, checked logs for interior rot, and checked for lead paint on surfaces such as window sills (Figure 2). The team took documentary photographs of each building and structure noting both character-defining features and areas of deterioration.

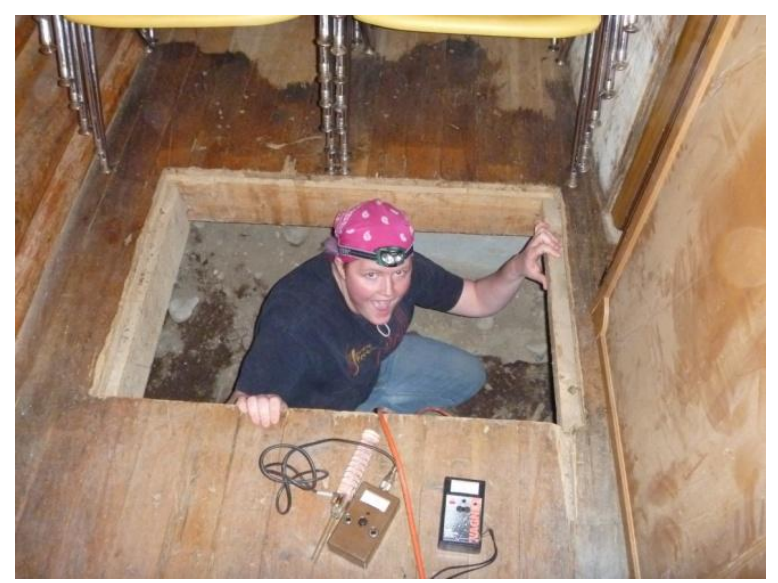

Figure 2. Student Cassie Loveland emerges after conducting moisture-level tests underneath the Berol Lodge at AMK Ranch. (Mary Humstone, 2011).

Following the initial assessment, the team interviewed Research Center director Hank Harlow and caretaker Rich Viola to learn about past and current maintenance procedures and building conservation challenges (Figure 3). The team identified several problems that were common to most of the buildings on the AMK Ranch, including improper roof flashing, improper site drainage, vegetation adjacent to buildings, varmints (bats and ants) and areas of wood rot.

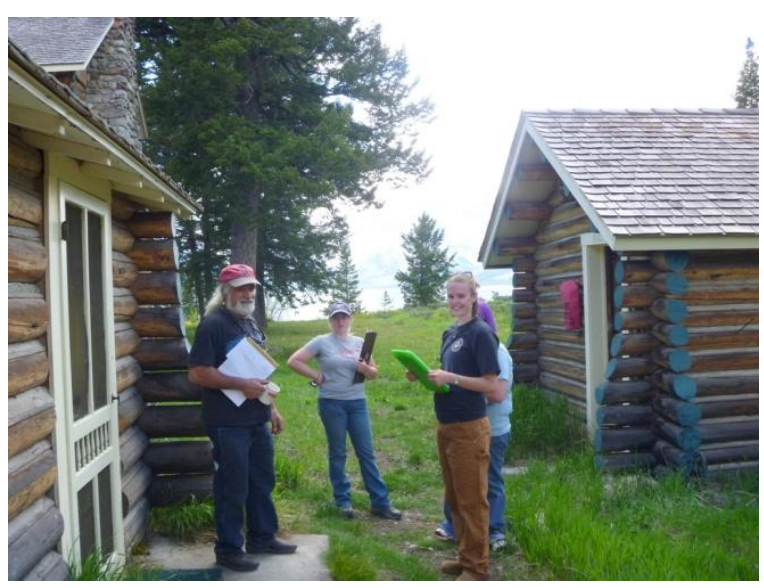

Figure 3. Students meet with Rich Viola, caretaker at AMK Ranch, to discuss maintenance and conservation issues. (Mary Humstone, 2011)

Once the problems were identified, the focus turned to solutions. The team spent a full day visiting other historic properties in the park to learn how other historic log buildings were being maintained and repaired. Their field visits included meeting with staff and touring the Western Center for Historic Preservation at the White Grass Ranch.

Although on-site time was limited, the team was able to conduct testing to determine the best procedures for cleaning logs. They also conducted training for on-site personnel in replacing daubing in log buildings.

Drawing from the expertise of Harrison Goodall, coupled with evidence from buildings at the AMK and other historic properties in the park and research on current rehabilitation practices and products, the team developed treatment procedures to address the major problems encountered in conserving historic buildings at the AMK Ranch.

\section{$\uparrow \quad$ Case Study: LogS}

One area of particular concern to Research Center director Hank Harlow and caretaker Rich Viola was the black fungus that was growing on the building logs. The research team determined that, due to the application of a preservative made up of linseed oil, turpentine, and paraffin every few years, the log buildings at the AMK Ranch were generally 
in good condition, especially compared with other log buildings in the park that have been painted, whitewashed, treated with other finishes or left untreated. However, while the linseed oil protects the logs, it acts as a food source for fungal growth which in turn causes the logs to darken (Figure 4). Additionally, linseed oil breaks down in ultraviolet (UV) light and flakes off, leaving logs unprotected. Because of these negative factors, it was determined this treatment should be discontinued, and replaced with application of borate (a natural log preservative, fungicide, and insecticide) and a UV-blocking preservative.

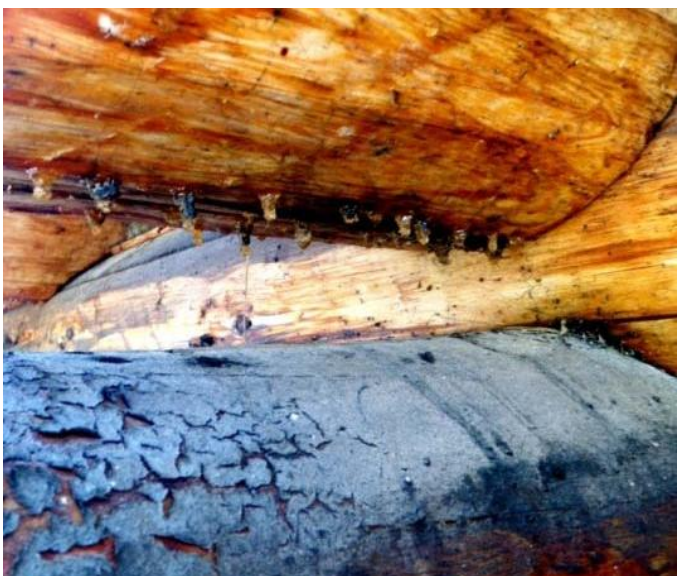

Figure 4. Black fungus growth on logs as a result of treatment with linseed oil. (Mary Humstone, 2011)

Unfortunately, the layers of linseed oil must be removed for the necessary treatments of borate and UV blocker to be effective. The team conducted a series of log-cleaning tests, using different products and different methods of abrasion (Figures 5 and 6). Care was taken to choose cleaning solutions that are non-toxic, such as vinegar, baking soda and biodegradable detergents.

\section{$\uparrow \quad$ Case Study: Bats}

Bats are a perennial problem at the AMK Ranch, especially the Berol Lodge, where they can be found in any dark, warm corner of the building, including along the ridgepole and purlins in the living room and the curtains in the hallway. Pests, including marmots, pine martens, ants and birds as well as bats, can cause serious damage to buildings from digging, nesting, urinating and otherwise inhabiting the buildings, both inside and outside. Bat guano can cause damage to any fibrous material, such as wood, carpet, furniture, and curtains. Bat guano and urine can cause health issues such as histoplasmosis, a lung disease, and bats have also been known to carry rabies.

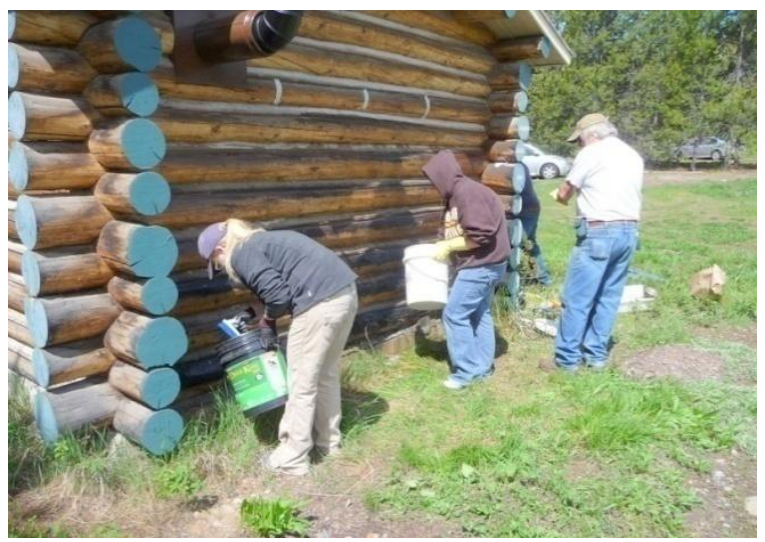

Figure 5. Team members prepare a log wall for testing to compare the effects of different log cleaning techniques. (Mary Humstone, 2011)

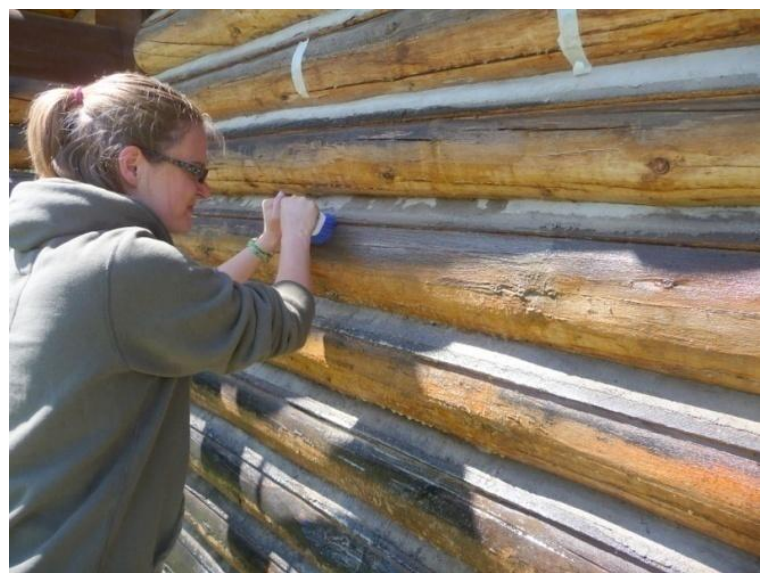

Figure 6. UW student Andrea Lewis cleans logs with abrasive brush after applying a cleaning solution. (Mary Humstone, 2011)

Because the AMK Ranch is within Grand Teton National Park, park-approved procedures for pest removal must be followed. Pests must be trapped and removed without harming them. Bats and other creatures should be removed when they are least likely to be impacted, which generally means avoiding mating and nesting seasons and waiting for offspring to mature.

Careful inspection of the Berol Lodge revealed the places where bats were entering and exiting the building. The team noted that the existing bat netting around the chimney had been improperly installed and therefore was ineffective. The team studied what methods of bat exclusion had been tried in the past and failed, and researched and analyzed alternative methods for excluding bats in order to come up with a recommended procedure for the AMK Ranch (Figure 7). 


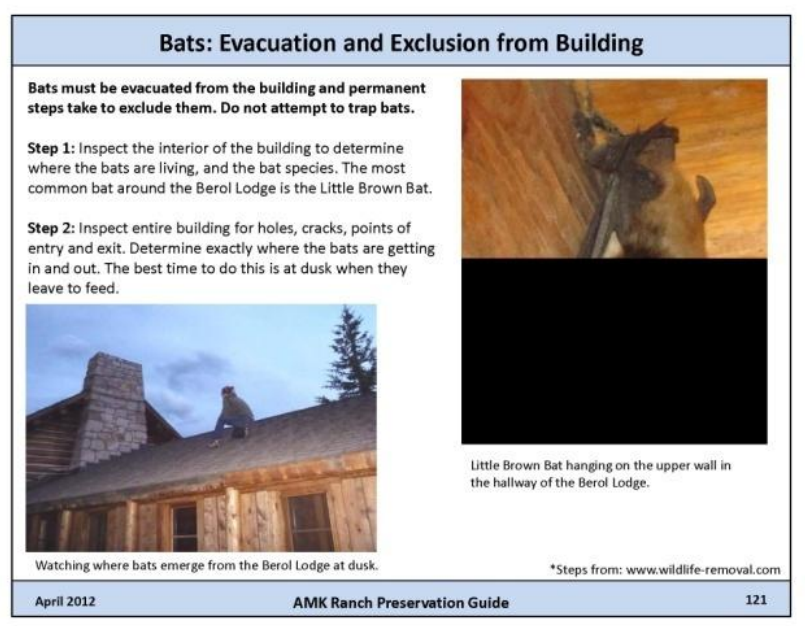

Figure 7. Page from Preservation Treatment Guide with step-by-step instructions for bat exclusion. (2011)

\section{$\uparrow \quad$ RESULTS}

The product of this research project is a Preservation Treatment Guide for AMK Ranch that includes photographs and building condition assessments for 16 buildings and 2 structures, procedures for remedying the major conservation problems, and a maintenance checklist. The guide will be used by University of Wyoming and National Park Service personnel, not only at AMK Ranch but at other locations in the park (Figure 8).

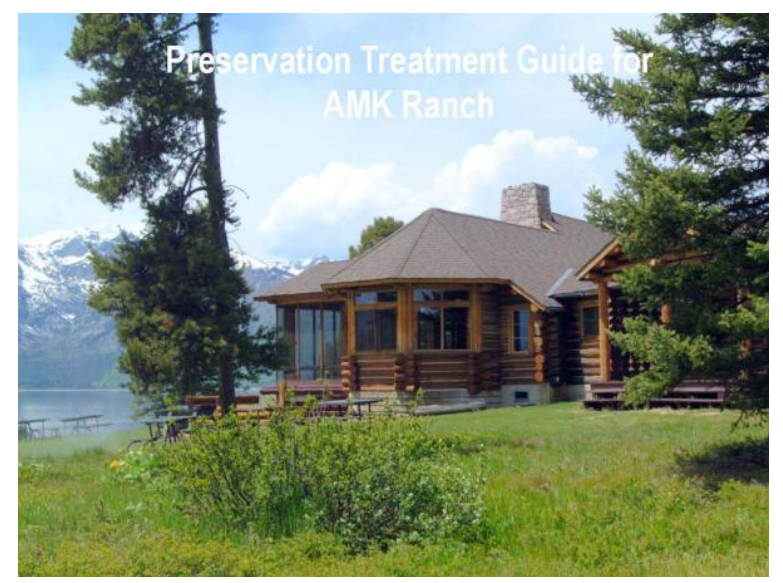

Figure 8. Cover of Preservation Treatment Guide (2011).

The Preservation Treatment Guide for the AMK Ranch provides building-by-building information as well as general treatment procedures for the most common historic preservation problems. The Introduction provides background information about the history and significance of AMK Ranch, and defines the general protocols for work on a National Register-listed property. This section includes The Secretary of the Interior's Standards for the Treatment of Historic Properties, customized for the AMK Ranch, and guidelines for proper documentation of preservation work (Figure 9).

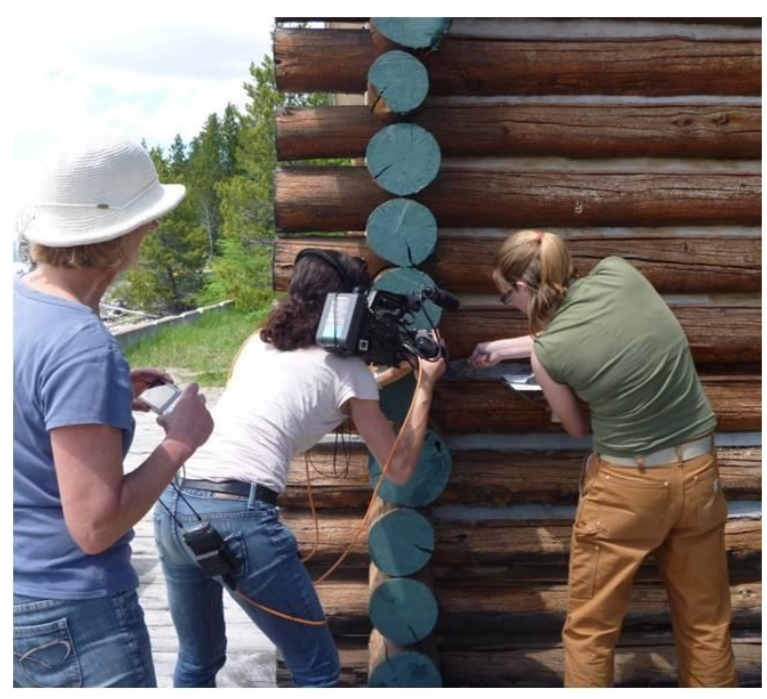

Figure 9. Documentation of log daubing at the AMK Ranch boat house. (Mary Humstone, 2011)

Chapter 2, Historic Buildings at the AMK Ranch, contains an illustrated list of the characterdefining features of each of the eighteen historic buildings and structures in the AMK Ranch Historic District, and an analysis of maintenance and repair problems and recommended solutions for each property (Figure 10). This section was designed to be used by property managers to create building-bybuilding files to document and monitor building conditions and treatments.

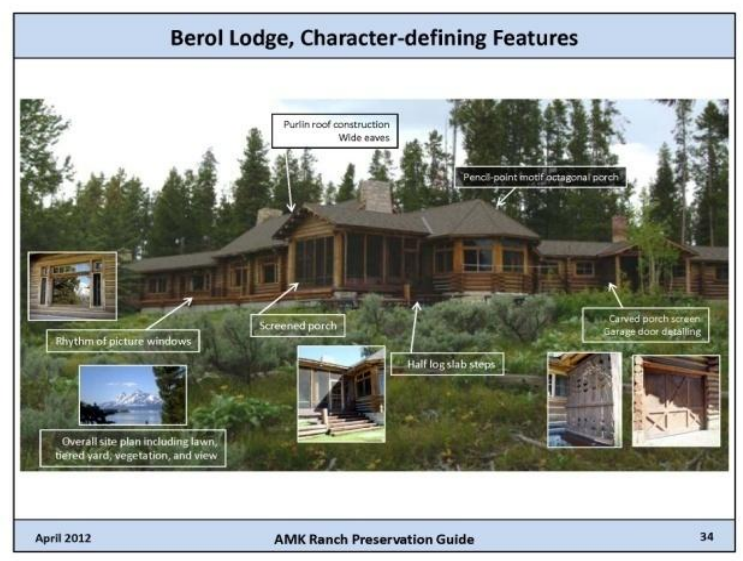

Figure 10. Page from Preservation Treatment Guide showing character-defining features of the exterior of the Berol Lodge.

Chapter 3, Addressing Problem Areas, provides specific procedures for the recommended solutions outlined in the previous section. 
Recommendations address issues such as exterior log maintenance, including cleaning, finish, daubing, replacing sill logs, splicing and repairing log crowns and faces (Figure 11); repairing roofs and chimneys; correcting faulty ventilation, flashing, grading and drainage; removing vegetation around buildings; maintaining and repairing windows and doors; snow removal and winterization; and controlling pests, including ants and bats. Specific problems relating to drainage around the Berol Lodge and repair of the southwest porch of the Berol Lodge are included in this chapter (Figure 12).

Chapter 4, Regular Inspection and Maintenance Tasks, lists tasks that should be performed annually, such as cleaning roofs, gutters, and valleys, cleaning the interiors and exteriors of each building, painting any surfaces where paint is peeling and chipping, hanging screens and storm windows as needed, blowing out log checks, and trimming vegetation around buildings. This chapter also explains use of the Building Condition Assessment Form to record annual building inspections. Regular inspections help identify maintenance problems, making deferred maintenance less likely. As soon as problems are identified, repair should be scheduled.

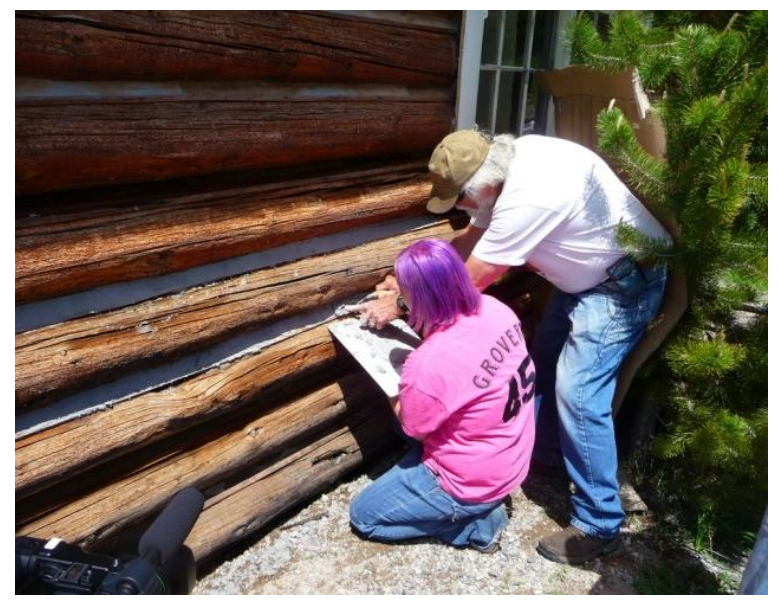

Figure 11. Harrison Goodall shows student Cassie Loveland how to apply daubing to the logs of the boathouse at AMK Ranch. (Mary Humstone, 2011)

The Appendix includes a CD with completed Building Condition Assessment Forms (2011) and blank forms for future use, as well as additional photographs and information on National Park Service policies.

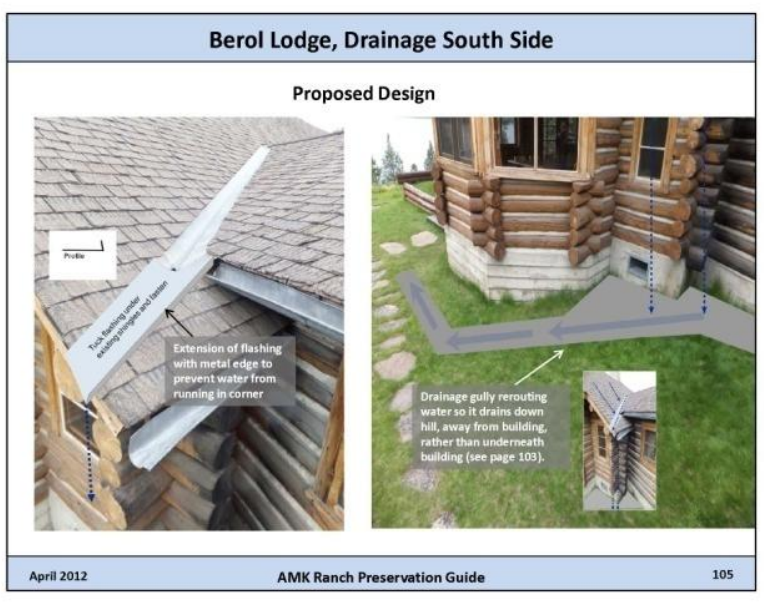

Figure 12. Page from Preservation Treatment Guide with step-by-step instructions for improving drainage at the Berol lodge. (2011)

\section{$\uparrow \quad$ ACKNOWLEDGEMENTS}

In addition to support from the UW-NPS Research Center, this project received funding from the Rocky Mountain Cooperative Ecosystems Studies Unit and the University of Wyoming American Studies Program. As graduate assistant on the project, Carly-Ann Anderson managed the compilation of material and the layout of the report. Students Sheila Bricher-Wade, Cassie Loveland and Andrea Lewis contributed building assessments and photographs, and researched and wrote up conservation protocols.

Harrison Goodall, Conservation Specialist and Katherine Longfield, Cultural Resources Manager at Grand Teton National Park, provided expertise in conservation of historic log buildings. Special thanks go to Dr. Hank Harlow, director of the UW-NPS Research Center, for supporting our research and field schools, and to caretaker Rich Viola for his care of the historic buildings at the AMK Ranch.

\section{Checklist of Preservation DOCUMENTS}

Cedar Shingle and Shake Bureau. Roof Manual. 2010. http://www.cedarbureau.org/installationand-maintenance/roof-manual/

Diem KL, Diem LL, Lawrence WC. 1986. A Tale of Dough Gods, Bear Grease, Cantaloupe, and Sucker Oil: Marymere/Pinetree/MaeLou/AMK Ranch. 
Goodall H. Conservation Guide, Murie Ranch Historic District, Moose, Wyoming, 2007.Customized Secretary of the Interior's Standards and Guidelines for the Murie Center, 2007.

Goodall H. 2007. Preservation Maintenance, Murie Center, Moose, Wyoming.

Goodall H. 2007. Preservation Maintenance Procedures, Murie Center, Moose, Wyoming, 2007. $\quad$ http://web.me.com/harrisongoodall/ Harrison/Conservation_Services.html

Henry MC. 2008. The Heritage Building Reinvestment Model, 2008. Materials in Older Buildings,2003. National Center for Preservation Technology and Training

Humstone M, Schill S. 2005. National Register of Historic Places Nomination for the AMK Ranch.

National Park Service Preservation Tech Notes http://www.nps.gov/history/hps/tps/technote s/tnhome.htm
National Park Service Preservation Tech Notes Secretary of the Interior's Standards for Rehabilitation and Guidelines for Rehabilitating Historic Buildins. http://www. nps.gov/hps/tps/standguide/rehab/rehab_standard $\underline{\text { s.htm }}$

National Park Service Preservation Tech Notes Understanding the National Park Service's Integrated Pest Management Program, 2003.

National Park Service Preservation Tech Notes Walk Through Historic Buildings. http://www.nps. gov/history/hps/tps/walkthrough

National Park Service. Preservation Briefs http://www.nps.gov/history/hps/tps/briefs/pres bhom.htm 